\title{
Study of the Adherence between Polymer-Modified Mortars and Porcelain Stoneware Tiles
}

\author{
Alessandra Etuko Feuzicana de Souza Almeida*, Eduvaldo Paulo Sichieri \\ Interunidades em Ciência e Engenharia dos Materiais, \\ Escola de Engenharia de São Carlos, Universidade de São Paulo \\ Av. Trabalhador São-carlense, 400, 13566-590 São Carlos - SP, Brazil
}

Received: May 20, 2004; Revised: March 20, 2005

\begin{abstract}
Despite the excellent characteristics of porcelain tiles, their application on building facades requires special attention, since this material differs from conventional ceramics and because facades are exposed to weathering that can damage ceramic revetments. The combination of polymer and silica fume to produce mortars results in excellent properties, which are ideal for repairs and revetments requiring high performance. Such improvements justify its study for the installation of porcelain tiles. This article presents bond strength results for mortars containing different amounts of polymer and silica indicating the applicability of these mortars as a construction material. To complement this study, the interface between the porcelain and the mortars was analyzed by scanning electron microscopy (SEM).
\end{abstract}

Keywords: porcelain tile, adhesion, mortar, silica fume, polymer

\section{Introduction}

The lower water absorption of porcelain tile makes it ideal for façade applications in buildings, preventing the occurrence of defects such as humidity-related expansion and detachment. The characteristics of the adhesive mortars must be different from those of the mortars usually employed to anchor more porous ceramic materials that have improved adherence by mechanical interlocking.

The adhesive mortars available in the market list adherence strength values obtained from tests with porous tiles. Therefore, the values of adherence for the application of porcelain are smaller, resulting in detachment problems and failure within short periods of time.

The purpose of this work was to investigate the effect of silica fume and acrylic polymer together on the adhesive properties of mortars employed to install porcelain stoneware tiles.

\section{Literature Review}

The ceramic tile system for external cladding includes the tiles, a substrate, a mortar to bond the tiles to the substrate, and a grouting material used to seal the gaps between the tiles. The success of the system depends on the perfect interaction between these parts that must provide impermeability properties to the entire system.

Porcelain stoneware tiles have been used more and more. They are considered a high technology product which offers extremely high aesthetical qualities, high wear resistance, almost zero percent of water absorption, high impact strength, chemical resistance, surface hardness, frost resistance and compressive strength ${ }^{1,2}$.

Thanks to their excellent characteristics, the porcelain tiles are currently employed as wall and floor coverings, and nowadays, also used in facades. Considering the very low water absorption of the material, it is essential to fix these tiles using an appropriated adhesive able to assure a good and everlasting adhesion. The poor adherence is a gap that needs studies since it causes serious accidents when porcelain tiles are applied on building facades.
Polymer modified mortars are being used as a popular construction material because of their excellent performance. The fundamentals about polymer modification for cement mortar and concrete have been studied for the past 70 years or more. The cement mortar and concrete made by mixing with the polymer-based admixtures are called polymer-modified mortar (PMM) and concrete (PMC), respectively ${ }^{3,4}$.

A polymeric admixture, or cement modifier, is defined as an admixture which consists of a polymeric compound that acts as a main ingredient for the modification or improvement of mortars and concretes properties such as strength, deformability, adhesion, waterproofness and durability. Polymer latex is a colloidal dispersion of small polymer particles in water, which is obtained by the emulsion polymerization of monomers with emulsifiers ${ }^{5,6}$.

The resultant physical properties of a latex-modified cement mortar are affected by those same variables that can affect unmodified Portland cement mortars and concretes, and by polymer typical properties such as solids content, $\mathrm{pH}$, density and minimum film formation temperature ${ }^{5,6}$. Acrylic polymers used with Portland cement are composed mainly of polyacrylates and polymethacrylates, resulting from the polymerization of derivatives of acrylic acids ${ }^{6}$.

The literature agrees that the properties of polymer-modified mortar and concrete depend significantly on the polymer content or polymer/cement ratio ${ }^{3,4-7}$.

Silica fume or microssilica is an industrial by-product from electric arc furnaces producing silicon and ferrosilicon alloys. It has been widely used as a concrete and mortar admixture, mainly to improve the mechanical properties and reduce the porosity. Due to the pozzolanic activity, a refinement of the concrete pore structure occurs and the properties are improved ${ }^{8,9}$.

Finely ground material such as silica fume can increase the water required for a given workability. Therefore, water reducing admixtures (or superplasticizers) are often used to improve the workability of mortars with silica fume ${ }^{8}$. 
The correct combination of silica fume, superplasticizer and polymeric emulsions may have the synergistic effects of these three admixtures, resulting in a construction material with good performance for many applications ${ }^{10,11}$. For this reason, this work is aimed to evaluate the effects of such admixtures on mortars properties, specifically the ones used to install porcelain tiles.

The silica fume and polymer latex addition can improve the mechanical properties as explained below ${ }^{11}$ :

- Water-reducing effect of polymer: polymer modifier reduces the water to cement ratio of mortar at the same flowability;

- Filling effect of polymer: polymer can fill microcracks, pores and cracks and so, impermeability and density can be improved;

- Pozzolanic effect: $\mathrm{SiO}_{2}$ in silica fume reacts with hydrates of cement, decreasing the quantity of $\mathrm{Ca}(\mathrm{OH})_{2}$, and decreases the volume of large pores, reducing the continuous pores in the cement paste; and

- Filling effect of fine particle: Such fine particles of silica fume complete cement particles with good grading, that improve the flowability of cement mortar.

\section{Materials}

\subsection{Cement and silica fume}

The mortars were prepared using high-early-strength Portland cement (CPV-ARI Plus according to NBR 5733 (type III according to ASTM C 595). The chemical and physical properties of the cement are shown in Tables 1 and 2, respectively, according to the manufacturer. The silica fume used was provided by Microssilica, Brazil, with a specific surface area of $27,740 \mathrm{~m}^{2} / \mathrm{g}$ (obtained by BET test), and $94.3 \% \mathrm{SiO}_{2}$ content.

\subsection{Aggregate}

Natural quartz sand was used with $0.6 \mathrm{~mm}$ maximum diameter, and classified as very fine sand with fineness modulus of 1.37, according to the Brazilian standard NBR 7217.

Table 1. The chemical compositions of cement obtained from the producer.

\begin{tabular}{lc}
\hline Chemical compositions & CPV-ARI-Plus $(\%)$ \\
\hline Loss on ignition & 3.10 \\
$\mathrm{SiO}_{2}$ & 18.99 \\
$\mathrm{Al}_{2} \mathrm{O}_{3}$ & 4.32 \\
$\mathrm{Fe}_{2} \mathrm{O}_{3}$ & 3.00 \\
$\mathrm{CaO}$ total & 64.75 \\
$\mathrm{MgO}$ & 0.68 \\
$\mathrm{SO}_{3}$ & 3.01 \\
$\mathrm{Na}_{2} \mathrm{O}$ & 0.03 \\
$\mathrm{~K}_{2} \mathrm{O}$ & 0.85 \\
$\mathrm{CO}_{2}$ & 1.81 \\
$\mathrm{RI}$ & 0.26 \\
$\mathrm{CaO}$ & 1.63 \\
\hline
\end{tabular}

Table 2. Physical properties of cement obtained from the producer.

\begin{tabular}{ccccccc}
\hline \multicolumn{2}{c}{$\begin{array}{c}\text { Setting time } \\
(\mathrm{min})\end{array}$} & Blaine & \multicolumn{4}{c}{ Compressive strength (MPa) } \\
surface area & \multicolumn{4}{c}{ NBR 7215} \\
Initial & Final & $\mathrm{m}^{2} / \mathrm{Kg}$ & 1 day & 3 days & 7 days & 28 days \\
\hline 150.78 & 226.25 & 467.9 & 27.87 & 43.57 & 48.69 & 56.16 \\
\hline
\end{tabular}

\subsection{Superplasticizer}

A superplasticizer provided by MBT Brazil I. C. was used, presenting chemical base sulfonated melamine, liquid aspect, density $1.11 \mathrm{~g} / \mathrm{cm}^{3}( \pm 0.02), \mathrm{pH}: 8.5 \pm 1,16.49 \%$ solid content.

\subsection{Polymer latex}

The polymer latex used was characterized as described below:

- Aqueous dispersion of styrene-acrylate copolymer with $49 \%$ to $51 \%$ total solids content; Viscosity Brookfield (RVT $415{ }^{\circ} \mathrm{C}$ ): 1,000-2,000 mPas; Density: $1.02 \mathrm{~g} / \mathrm{cm}^{3}$; $\mathrm{pH}$ value: 4.5 to 6.5 ;

- Minimum film-forming temperature: $20{ }^{\circ} \mathrm{C}$;

- Mean size of particles: $0.1 \mu \mathrm{m}$;

- Film properties: Clear and transparent; and

- Stability to ageing: good.

\subsection{Porcelain stoneware tile}

The following properties were obtained for the porcelain stoneware tiles characterization:

- Determination of water absorption (NBR 13818 - Annex B): $0.2 \%$

- Determination of linear thermal expansion coefficient (NBR 13818 - Annex K): $\alpha\left(25\right.$ to $\left.325^{\circ} \mathrm{C}\right)=70.9 \times 10^{-7}$; and

- Determination of resistance to thermal shock (NBR 13818 - Annex L): failures not detectable after 10 cycles.

\section{Experimental Program}

The standard substrate was prepared according to the Brazilian standard NBR 14082, which specifies the use of Portland cement, sand and gravel, with a water-cement ratio of 0.45 to 0.50 , a minimum cement content of $400 \mathrm{~kg} / \mathrm{m}^{3}$ and mass proportions of materials of $1: 2,58: 1,26$. The substrates were characterized by capillary absorption (NBR 14082).

Eight different mortars were prepared as described in Table 3. The materials were weighted and mixed in a planetary-type mortar mixer. The cement-sand ratio of 1:1.5 by mass was adopted for the mortars. The amount of water added to the mixture varied in order to ensure proper workability when applying the mortars. A superplasticizer was added in proportion of $1 \%$ by weight of cement.

In order to compare the results, a commercial mortar was studied and prepared according to the producer instructions.

The application of the mortars on the substrate was carried out following the specifications of the Brazilian standard NBR 14082.

Table 3. Mix proportion of mortars.

\begin{tabular}{ccccc}
\hline $\begin{array}{c}\text { Designation } \\
\text { of mortar }\end{array}$ & $\begin{array}{c}\text { Silica fume } \\
\text { content } \\
(\%)^{*}\end{array}$ & $\begin{array}{c}\text { Polymer } \\
\text { Latex } \\
\text { content } \\
(\%)^{*}\end{array}$ & $\begin{array}{c}\text { Content of } \\
\text { polymeric } \\
\text { solids } \\
(\%)^{*}\end{array}$ & $\begin{array}{c}\text { Water/ } \\
\text { cement } \\
\text { ratio }\end{array}$ \\
\hline Ref 1 & 5 & 0 & 0 & 0.38 \\
A1 & 5 & 5 & 2.6 & 0.38 \\
A2 & 5 & 10 & 5.2 & 0.36 \\
A3 & 5 & 15 & 7.8 & 0.33 \\
A4 & 5 & 20 & 10.4 & 0.31 \\
Ref 2 & 10 & 0 & 0 & 0.37 \\
A5 & 10 & 5 & 2.6 & 0.37 \\
A6 & 10 & 10 & 5.2 & 0.36 \\
A7 & 10 & 15 & 7.8 & 0.33 \\
A8 & 10 & 20 & 10.4 & 0.31 \\
\hline *by mass of cement & & & &
\end{tabular}


Using a notched steel trowel having a $6 \mathrm{~mm} \times 6 \mathrm{~mm}$ notches, the mortar was carefully spread on the substrate in straight, even ridges. Commercial porcelain tiles were cut in $35 \mathrm{~mm}$ diameter pieces, which were then placed onto these mortar ridges.

After 27 days of storage under standard conditions, that is $23{ }^{\circ} \mathrm{C}$ and relative humidity of $(60 \pm 2) \%$, metallic pull head plates were then glued onto the porcelain tiles using epoxy adhesive. These metallic plates were connected to the test machine for the direct pull off tensile test. After 24 hours of storage, the tests were performed following the procedures described in the standard NBR 14084.

Pore structure was observed by scanning electron microscopy (SEM) on flat polished sections of the samples showing the interface formed between the mortar and the porcelain tile, obtained after the adhesion test procedures.

\section{Results and Discussion}

The values of the tensile load applied by the machine to pull off the porcelain fixed onto the underlying mortar ridges were obtained. This load is divided by the bonding area of the tile to determine the tensile adhesion strength (bond strength).

Figure 1 shows the bond strength results obtained for the studied mortars, indicating that the addition of polymer and silica fume improved the bond strength. The higher the admixtures contents, the higher the bond strength, for the reason that the latex addition decreases the water/cement ratio, besides the polymer forms linking bridges that improve the adhesion. A statistical analysis was performed, as can be seen in the Table 4, showing the mean, standard deviation and the maximum and minimum values. The values of standard deviations are justified because the procedures performed were mainly manual, besides the mortars can be classified as heterogeneous product.

As for the mode of rupture, it was found that the rupture of mortars A2, A3, A4, A5 and A8 occurred at the mortar-substrate interface (Figures 2 and 3). Hence, it can be stated that, in these cases, the bond strength between the porcelain and the mortar was higher than the bond between the mortar and substrate.

It was found that, in the case of mortars with $10 \%$ silica fume and $10 \%$ latex, $10 \%$ silica fume and 15\% latex (A6 and A7, respectively), the rupture occurred more frequently between the porcelain tile and the mortar, as showed in the Figure 3. We believe the substrate's porosity favored the adherence with the mortar, and that the addition of polymer and silica fume increased these mortars' mechanical strength.

Table 4. Descriptive statistic performed for the bond strength values.

\begin{tabular}{ccccc}
\hline $\begin{array}{c}\text { Silica } \\
\text { content } \\
(\%)\end{array}$ & $\begin{array}{c}\text { Latex } \\
\text { content } \\
(\%)\end{array}$ & $\begin{array}{c}\text { Number of } \\
\text { observations }\end{array}$ & $\begin{array}{c}\text { Mean values } \\
\text { of bond } \\
\text { strength } \\
(\mathrm{MPa})\end{array}$ & $\begin{array}{c}\text { Standard } \\
\text { deviation }\end{array}$ \\
\hline $5 \%$ & $0 \%$ & 7 & 1.28 & 0.25 \\
$5 \%$ & $5 \%$ & 9 & 0.40 & 0.23 \\
$5 \%$ & $10 \%$ & 10 & 0.83 & 0.14 \\
$5 \%$ & $15 \%$ & 11 & 1.45 & 0.23 \\
$5 \%$ & $20 \%$ & 11 & 1.70 & 0.24 \\
$10 \%$ & $0 \%$ & 6 & 1.03 & 0.25 \\
$10 \%$ & $5 \%$ & 7 & 0.91 & 0.11 \\
$10 \%$ & $10 \%$ & 10 & 1.52 & 0.36 \\
$10 \%$ & $15 \%$ & 9 & 1.71 & 0.35 \\
$10 \%$ & $20 \%$ & 7 & 1.83 & 0.42 \\
Commercial mortar & 10 & 1.24 & 0.14 \\
\hline
\end{tabular}

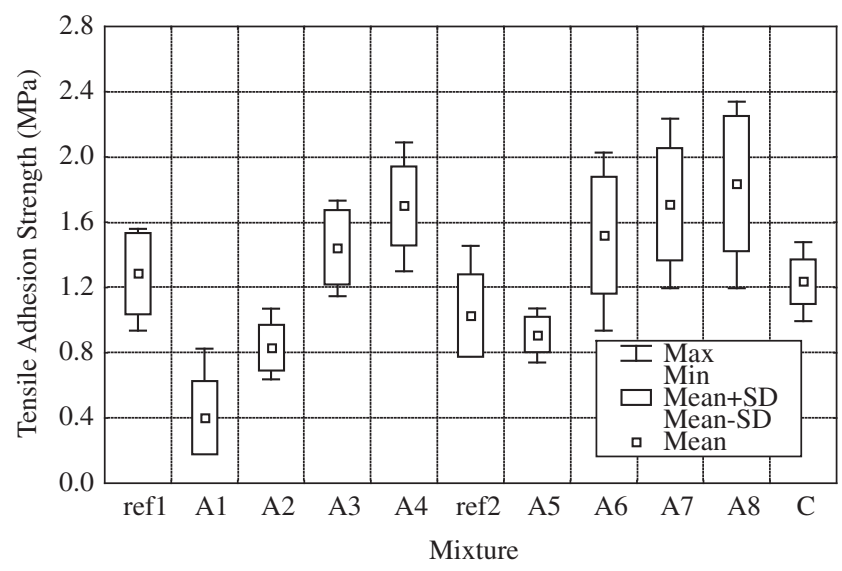

Figure 1. Box plots of the tensile bond strength results. Ref 1 (5\% silica, $0 \%$ latex); A1 (5\% silica, 5\% latex); A2 (5\% silica 10\% latex); A3 (5\% silica, $15 \%$ latex); A4 (5\% silica, 20\% latex); ref 2 (10\% silica, $0 \%$ latex); A5 (10\% silica, 5\% latex); A6 (10\% silica, 10\% latex); A7 (10\% silica, 15\% latex); A8 (10\% silica, $20 \%$ latex); C (commercial mortar).

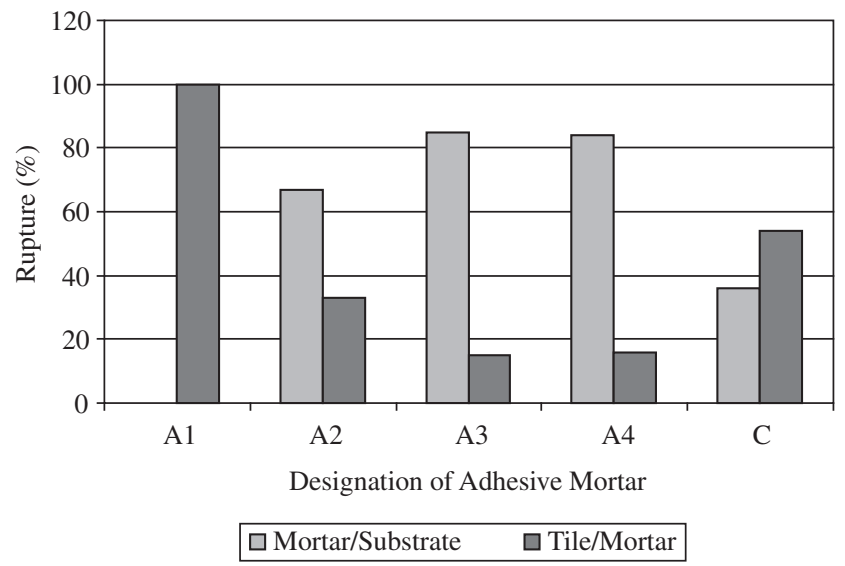

Figure 2. Rupture (\%) resulting from the tensile bond strength test.

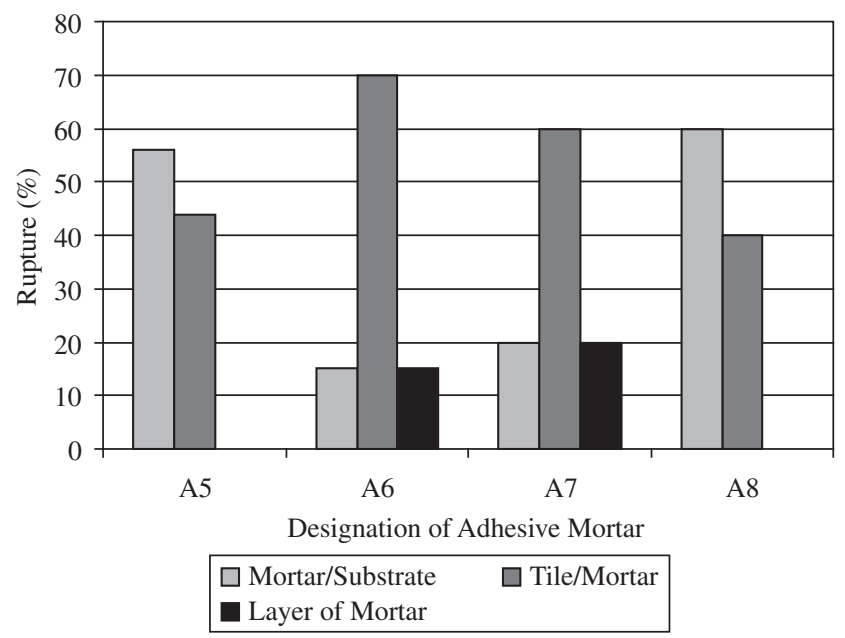

Figure 3. Rupture (\%) resulting from the tensile bond strength test. 
Some procedures for testing adherence may influence test results. The porcelain tile was cut and installed onto the mortar following the Brazilian standard NBR 14084. During the testing procedures, it was found that, in cases where the fracture occurred at the mortar-substrate interface, the mortar layer underwent high shear stresses before the rupture occurred, which is also a way of evaluating the mortar's mechanical strength, not only the tensile bond strength. In this way, it seems that the values obtained when the adhesive mortar layer is also cut down to the substrate underestimate these shear stresses.

By means of scanning electron microscopy in the backscattered electron mode, it is possible to distinguish anhydrous phases (bright particles) from the hydrated products (gray phase), and the air-voids (black zone).

Figures 4, 5 and 6 show micrographs by backscattered electrons mode of the interface formed between the porcelain tile and mortars. Mortars with additions showed a denser hydrated product phase than commercial mortar, moreover, porosity is reduced mainly in the interface between the mortar and the porcelain tile.

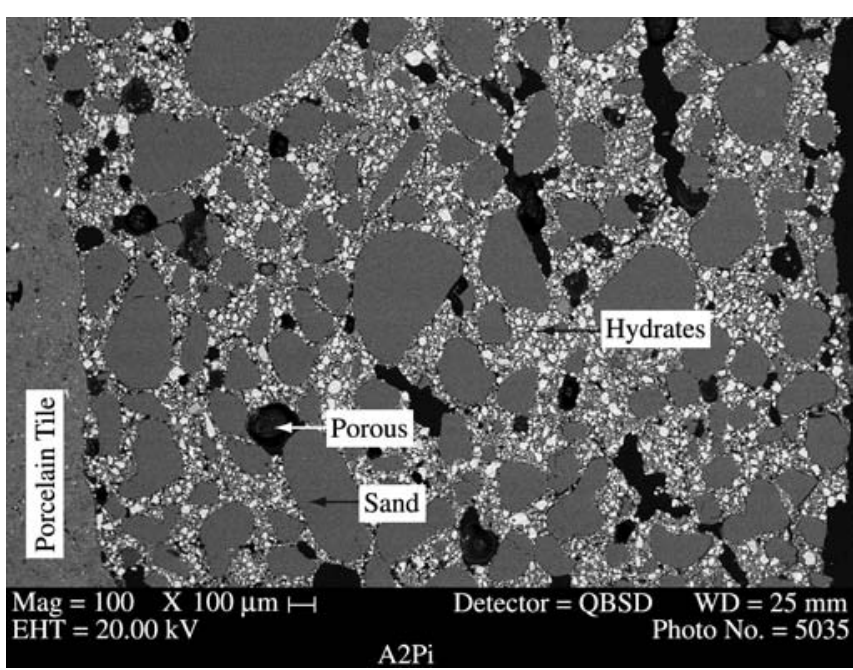

Figure 4. Backscattered electron micrograph of the polished surface. showing the interface between porcelain tile and mortar containing $5 \%$ silica fume and $20 \%$ latex.

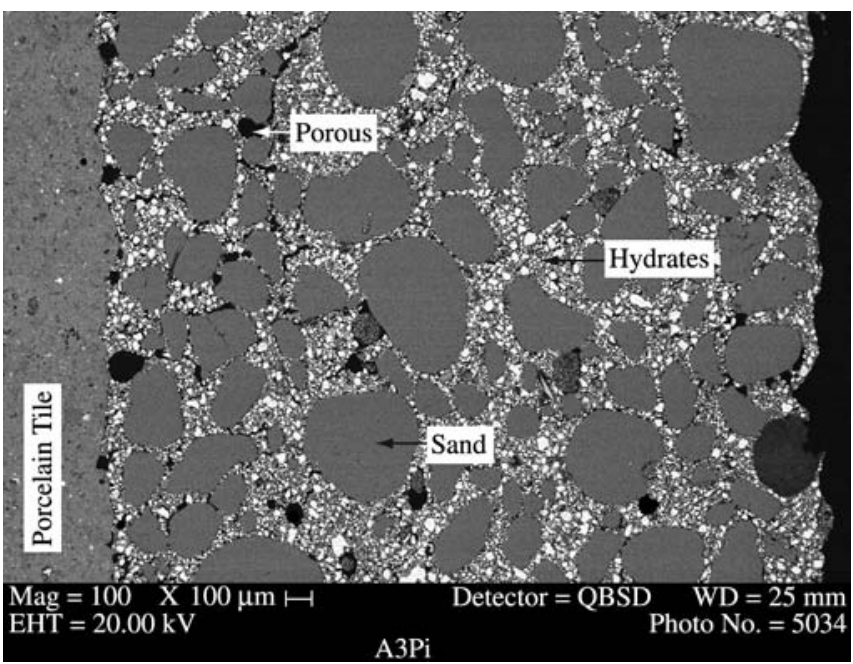

Figure 5. Backscattered electron micrograph of the polished surface. showing the interface between porcelain tile and mortar containing $5 \%$ silica fume and $20 \%$ latex.
Figure 7 shows commercial mortar microstructure with largeshaped air voids (black zone) and a lesser amount of hydrated products (gray phase).

\section{Conclusions}

The analysis of the results leads to the following conclusions:

- For each result obtained, it is important to correlate the mode of rupture, the tensile adhesion strength and the materials constituting the mortars;

- The amount of polymer in the mortars alters their properties, such as their consistency, at the moment they are applied. As the amount of polymer increases, so does the mortar's plasticity and workability, making it easier to spread over the substrate and forming higher and well-defined ridges. The porcelain tiles adhered to the mortars more easily in the case of mortars with greater polymer content; and

- Additions of silica fume and latex reduced the air-voids content and improved the hydrated products as a result of the poz-

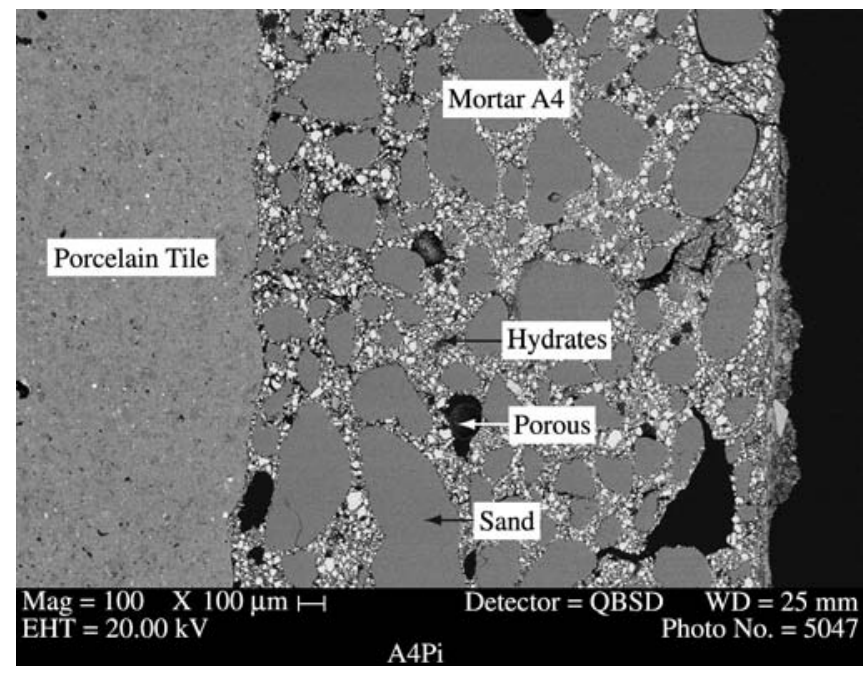

Figure 6. Backscattered electron micrograph of the polished surface. showing the interface between porcelain tile and mortar containing 5\% silica fume and $20 \%$ latex.

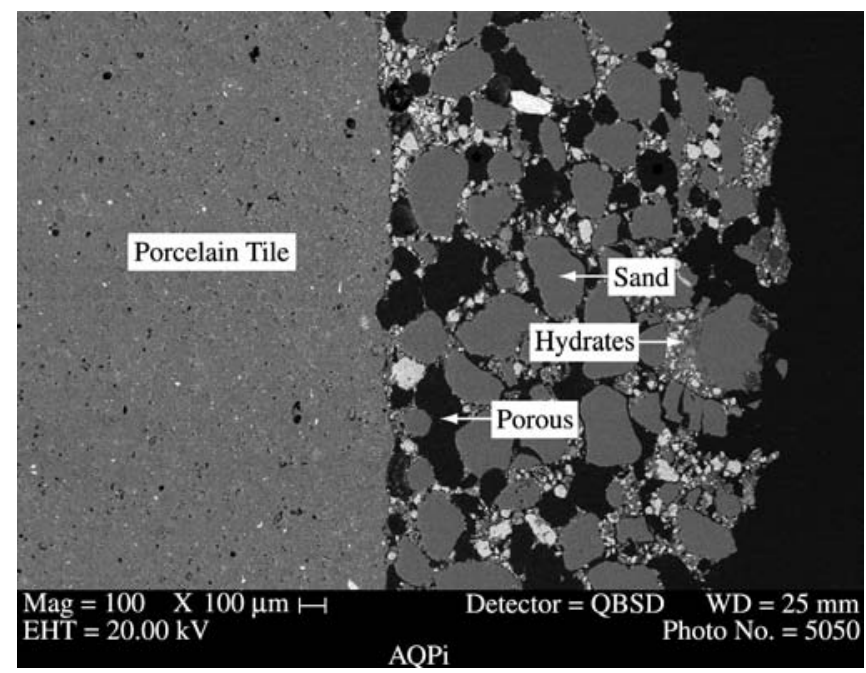

Figure 7. Backscattered electron micrograph of the polished surface. showing the interface between porcelain tile and commercial mortar. 
zolanic reactions and latex effect, as mentioned in the literature review. In this way, the adherence between the mortar and the porcelain tile was improved due to the greater area of contact between them.

These findings indicate the advantages resulting from the addition of polymer and silica fume to mortars, since the results were superior to those specified by the standard (1 MPa). However, the author will continue this study in order to guarantee a stable and reliable fixing of the porcelain stoneware tiles.

\section{Acknowledgments}

The authors would like to acknowledge the financial support from FAPESP.

\section{References}

1. Biffi G. Gres Porcellanato - Tecnologia, produzione, mercato. Faenza, Itália: Gruppo Editoriale Faenza; 1994.

2. Oliveira APN. Grês porcelanato: Aspectos Mercadológicos e Tecnológicos. Cerâmica Industrial. 1998; 3(3):34-41.
3. Ohama Y. Polymer based admixtures. Cement and Concrete Composites. 1998; 20:189-212.

4. Fowler DW. Polymers in concrete: a vision for the 21 st century. Cement and Concrete Composites. 1999; 21:449-452.

5. Walters DG. What are latexes? Concrete International. 1987; 9(12):4447.

6. Lavelle JA. Acrylic latex-modified portland cement. ACI Materials Journal. 1998; 85(1):41-48.

7. Ohama Y. Recent progress in concrete-polymer composites Advanced Cement Based Materials. 1997; 5:31-40.

8. Aïtcin Pierre-claude. Concreto de Alto Desempenho. São Paulo: Ed. Pini; 2000.

9. Male P. Properties of microssilica. Concrete. 1989; 23(8):31-34.

10. Chakraborty AK, Dutta SC, Sen P, Ray I. Improved performance of silica fume modified mortar due to addition of polymer emulsions. Journal of Polymer Materials. 2000; 17(1):53-62.

11. Gao JM, Qian CX, Wang B, Morino K. Experimental study on properties of polymer-modified cement mortars with silica fume. Cement and Concrete Research. 2002; 32:41-45. 